\title{
Prognostic Risk Factors for Surgery in Patients with Cirrhotic Portal Hypertension
}

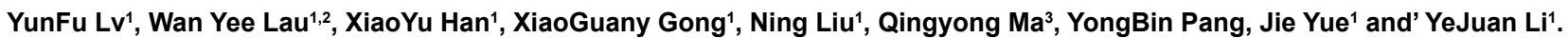

${ }^{1}$ Department of General Surgery, Hainan Provincial People's Hospital, Haikou, PR China

${ }^{2}$ Faculty of Medicine, The Chinese University of Hong Kong, PR China

${ }^{3}$ Department of Hepatobiliary Surgery, First Affiliated Hospital of Medical College, Xi'an Jiaotong University, Xi'an 710061, PR China

${ }^{4}$ Yanan University Affiliated Hospital, PR China

\section{Abstract}

Background: In the clinical management of cirrhotic portal hypertension, surgery is often necessary; however, the operative mortality rate is high.

Methods: Data from 161 patients who underwent surgery for cirrhotic portal hypertension were analyzed, and 24 potential predictors of surgical outcome were assessed. A Kruskal Wallis rank sum test was used for single-factor comparisons, and multivariate logistic regression for multi-factor comparisons to identify risk factors for poor surgical outcomes and calculate their scores.

Results: Six predictors of poor surgical outcomes were identified: postoperative bleeding within $30 \mathrm{~h}$ of $>2 \mathrm{~L}$, with a score of 3; severe liver atrophy (an anteroposterior diameter of the left lobe of $\leq 55 \mathrm{~mm}$ and an oblique diameter of the right lobe $\leq 110 \mathrm{~mm}$ ), with a score of 3 ; a base excess of <-3mmol/L, with a score of 3 ; a platelet count of $<3 \mathrm{~T} / \mathrm{L}$, with a score of 2; an amount of intraoperative bleeding of $>2 \mathrm{~L}$, with a score of 2; and a red blood cell count of $<3 \mathrm{G} / \mathrm{L}$, with a score of 1 . For patients with a good outcome $(n=147)$, all patients had a score of $\leq 3$, except one patient who had a score of 4 . With respect to patients that died $(n=14)$, all had a score of $\geq 5$, except one patient who had a score of 4 . A significant difference was observed between the two groups $(P<0.05)$. The mortality was $100 \%$ in patients with a score of $\geq 7$.

Conclusions: Six risk factors for poor surgical outcomes were identified in this study. Operative mortality appears to be significantly increased in patients with a score of 5-6. Surgery should be contraindicated in patients with a score of $\geq 7$. To reduce mortality, close attention should be paid to preoperative and intraoperative treatment and prevention to achieve a score of $<4$.

\section{Keywords}

Cirrhotic portal hypertension; Surgical prognosis; Risk factors

\section{Introduction}

Splenomegaly caused by viral hepatitis-induced cirrhotic portal hypertension is very common in clinical practice. Approximately 360 million carriers of hepatitis B virus (HBV) exist worldwide, and more than half of them are from the Asia-Pacific region. HBV infection occurs commonly in China, with an incidence of $9.8 \%$. On average, $20 \%$ of HBV-infected patients develop chronic hepatitis, [1] and 50\% develop cirrhotic portal hypertension. Similarly, there are approximately 170 million carriers of hepatitis C virus (HCV) worldwide, with $40 \%-50 \%$ developing chronic hepatitis, and $25 \%$ developing cirrhotic portal hypertension.

In recent years, the number of patients with cirrhotic portal hypertension that require surgery has decreased significantly. However, in patients with cirrhotic portal hypertension, $35 \%$ of cases have $\leq 50,000$ platelets in blood circulation, $40 \%$ of cases have a history of upper gastrointestinal hemorrhage, [2] and 18-23\% of cases are complicated by liver cancer $[3,4]$. The majority of these patients requires surgery, with a goal of staunching bleeding, eliminating splenomegaly and severe hypersplenism (hereinafter referred to as hypersplenism), and resecting liver tumors; however the surgical risks are great and the mortality rates are high. To investigate the reasons for this, a prospective study was performed to identify risk factors prognostic of surgical outcome in 161 patients with cirrhotic portal hypertension admitted and treated by the authors' hospital from January 2000 to June 2012. The risk factors were scored and the scores were used to evaluate their effects on surgical prognosis.

\section{Enrollment criteria}

Patients with portal hypertension due to cirrhosis were included, as were patients with splenomegaly complicated by hematocytopenia of one or multiple cell lines in the circulatory blood. The protocol required that patients enrolled had already undergone surgery, and required complete clinical data for all patients.

This study excluded patients with non-cirrhotic portal hypertension, such as regional portal hypertension, patients with no evidence of splenomegaly or hematocytopenia of one or multiple cell lines in the circulatory blood.

\section{Clinical data}

Of the 161 patients enrolled, 97 were male and 64 female (male: female=1.5:1). The ages of patients ranged from 10 to 64 years and averaged 42 years. One hundred twenty-two patients had liver cirrhosis secondary to HBV-hepatitis, 26 patients had liver cirrhosis secondary to HCV-hepatitis, 5 had biliary cirrhosis, 3 had alcoholic cirrhosis, 2

*Corresponding author: YunFu Lv, Department of General Surgery, Hainan Provincial People's Hospital, Haikou, PR China, Tel: 86-898-66528115 Fax: 91-172-2744401; E-mail: yunfu_Iv@126.com

Received May 26, 2014; Accepted September 22, 2014; Published September 26, 2014

Citation: Lv YF, Lau WY, Han XY, Gong XG, Liu N, et al. (2014) Prognostic Risk Factors for Surgery in Patients with Cirrhotic Portal Hypertension. J Hypertens 3: 172. doi:10.4172/2167-1095.1000172

Copyright: @ 2014 Lv YF, et al. This is an open-access article distributed under the terms of the Creative Commons Attribution License, which permits unrestricted use, distribution, and reproduction in any medium, provided the original author and source are credited. 
had schistosomial cirrhosis, 2 had autoimmune cirrhosis, and 1 had drug cirrhosis. Endoscopy or upper gastroenterography indicated moderate or severe varices in both the lower esophagus and stomach fundus. The entire group suffered with splenomegaly, which was palpable. Spleens palpable $<5 \mathrm{~cm}$ from the left rib arch were categorized as first (I) degree splenomegaly (70 cases), those palpable $>5 \mathrm{~cm}$ to the navel were categorized as second (II) degree splenomegaly (60 cases), and those below the umbilicus were categorized as third (III) degree splenomegaly ( 31 cases). The average spleen size was $224 \mathrm{~mm} \times 159$ $\mathrm{mm} \times 95 \mathrm{~mm}$ as measured by ultrasonography or CT. The indications for surgery included digestive tract hemorrhage of $\geq 500 \mathrm{ml}(\mathrm{n}=85)$, splenomegaly with PLT $<5 \times 10^{9} / \mathrm{L} \quad(\mathrm{n}=45)$, and hypersplenism with pancytopenia $(n=31)$. All patients underwent splenectomy. In addition, some patients received extensive devascularization around the cardia $(\mathrm{n}=31)$, splenorenal shunt $(\mathrm{n}=16)$, mesocaval shunt $(\mathrm{n}=10)$, and portacaval shunt $(n=4)$. Postoperatively, 32 patients $(19.9 \%)$ clinically recovered, 115 (71.4\%) improved, and 14 (8.7\%) died.

\section{Methods}

According to the regularly accessed common clinical indicators and the contents of pre-registration forms, information regarding 24 predictors including age, gender, degree of liver atrophy, ChildPugh classification, coagulation profile, spleen size, renal function, blood $\mathrm{pH}$ value, Base Excess (BE), operative time, ascites volume, and intraoperative and postoperative hemorrhaging volume was collected and statistically summarized. For each of the predictors, 2-3 different quantitative subgroups were set up to carry out comparisons.

The software package SPSS 18.0 was used for statistical analysis. Single factors were compared using the Kruskal-Wallis rank sum test to filter statistically significant $(P<0.05)$ predictors, followed by an integrated multiple logistic regression analysis, to filter risk factors impacting surgical prognosis. Furthermore, according to the proportion of these prognosis factors using the multiple regression equation $\hat{Y}=b 0+b 1 X_{1}+b 2 X_{2} \ldots$, their impacts on surgery were sorted, rated, and investigated.

\section{Results}

\section{Single-factor analysis}

After undergoing the Kruskal-Wallis rank sum test, age, sex, blood urea, serum creatinine, fibrinogen (Fib), oxygen partial pressure $\left(\mathrm{PO}_{2}\right)$, total bilirubin, and free portal venous pressure were observed to have no significant correlation with prognosis $(P>0.05)$. Sixteen factors, including liver volume, Child-Pugh classification, Prothrombin Time (PT), serum albumin, degree of esophageal varices, spleen size, Platelet (PLT) count, White Blood Cell (WBC) count, Red Blood Cell (RBC) count, Hemoglobin $(\mathrm{Hb})$, blood $\mathrm{pH}, \mathrm{BE}$, ascites volume, operative time, and intraoperative and postoperative wound bleeding volume within $30 \mathrm{~h}$ had a significant correlation with prognosis $(P<0.05)$, as shown in Tables 1 and 2 .

\section{Multi-factor analysis}

Using the 16 single factors that were significantly correlated with prognosis, an integrated multiple logistic regression analysis was performed, and the 6 predictors that had a significant correlation $(P$ $<0.05$ ) with diagnosis were filtered as risk factors (Table 3 ).

\section{Scoring of risk factors}

The 6 risk factors were scored based on sorting by the multiple regression equation and permissible clinical experience (Table 4), which were used to select surgery type and to assess prognosis, as well as to suggest preventive therapy for abnormal indexes prior to operation.

According to the scores in Table 4, of the 147 cases in the clinically recovered and improved group, 1 had a total score of 4 points, 12 cases had 3 points, 17 had 2 points, 26 had 1 point, and 91 had 0 points. Of the 14 cases in the group that died, except for one who received 4 points, all had a total score of over 5 points, including 2 with 5 points, 4 with 6 points, 2 with 7 points, 2 with 8 points, and 3 with 9 points (Figure 1). The difference between the two groups was significant $(P<0.05)$. There was a significant difference in mortality between the two groups $(P<0.001)$.

\section{Discussion}

Using a logistic regression analysis, 6 risk factors closely related to operative prognosis were identified. Of the 6 risk factors, intraoperative and postoperative wound hemorrhage volumes were not predictive, while 4 other factors were determined to be predictive and evaluable, and could be added for a total score. In total, 146 patients had a total score of $\leq 3$ points and no death occurred. A total score of 4 points was the shared central area for the recovered and improved group and the death group (one patient in each). To reduce mortality, patients should be actively treated preoperatively to maintain the total score within 4 points or less. With a total score of 5-6 points, patients are at risk of surgical mortality, so special care should be taken when selecting the type of surgery. Seven patients had a total score of $\geq 7$ points, with a mortality of $100 \%$; a total score of $\geq 7$ points should be classified as a surgical contraindication. This scoring method is based on sorting by the multiple regression equation (see Multi-factor analysis and Scoring of risk factors in the Results section). Such scoring not only avoids aimless operation, but also provides a theoretical basis for intensifying preoperative treatment.

Postoperative major wound bleeding refers to wound bleeding volumes of $>2 \mathrm{~L}$ within $30 \mathrm{~h}$ after surgery, and is the top risk factor impacting surgical prognosis (which was awarded 3 points). Of the 14 deaths in this study, 3 died of postoperative major wound bleeding, while 0 of the 147 patients in the recovered and improved group had postoperative major wound bleeding. Postoperative major wound bleeding is generally accompanied by intraoperative wound bleeding. In the single- and multi-factor analyses, intraoperative major wound bleeding was significantly associated with prognosis $(\mathrm{P}<0.05)$; it was awarded 2 points and ranked 6th in the overall group of risk factors. In this group, 10 patients experienced intraoperative major wound bleeding and 3 died (33.3\%). Several reasons for major wound bleeding exist. First, abnormal coagulation factors may play a role. In the single-factor analysis, a PT of $>30$ seconds was significantly correlated with prognosis ( $\mathrm{H}$ value of $13.026, P=0.001$ ). As such, a preoperative plasma transfusion is required to attempt to decrease PT to within 20 seconds. Fibrinogen (Fib), which is synthesized and secreted by liver cells, is an important physiological factor in physiological hemostasis. Although the effect of Fib was not obvious in the single-factor or multi-factor analysis, Fib that is too low will extend PT, activated partial thromboplastin time (APTT), and thrombin time, resulting in extensive blood oozing from the wound surface. This is even more prominent when complicated by significantly prolonged PT. Two patients in this group with a Fib of $\leq 1.4 \mathrm{~g} / \mathrm{L}$ and significantly prolonged PT experienced extensive exudation from the peritoneo-serosal surface and blood oozing from the wound surface immediately before the end of the splenectomy and portoazygous devascularization. These patients died despite resuscitation attempts. An effective way to elevate 
Citation: Lv YF, Lau WY, Han XY, Gong XG, Liu N, et al. (2014) Prognostic Risk Factors for Surgery in Patients with Cirrhotic Portal Hypertension. J Hypertens 3: 172. doi:10.4172/2167-1095.1000172

Page 3 of 6

\begin{tabular}{|c|c|c|c|c|c|c|c|}
\hline \multicolumn{2}{|l|}{ Predicators } & $\begin{array}{l}\text { Total case } \\
\text { number }\end{array}$ & Recovered (\%) & Improved (\%) & Died (\%) & Value of $\mathrm{H}$ & $\mathbf{P}$ \\
\hline \multirow{2}{*}{ Sex } & Male & 131 & $24(18.3)$ & $94(71.8)$ & $13(9.9)$ & \multirow[b]{2}{*}{2.072} & \multirow[b]{2}{*}{0.355} \\
\hline & Female & 30 & $8(26.7)$ & $21(70.0)$ & $1(3.3)$ & & \\
\hline \multirow{3}{*}{ Age (y) } & $<30$ & 17 & $5(29.4)$ & $10(58.8)$ & $2(11.8)$ & \multirow{3}{*}{1.22} & \multirow{3}{*}{0.543} \\
\hline & $30-60$ & 115 & $22(19.1)$ & $83(72.1)$ & $10(8.8)$ & & \\
\hline & $>60$ & 29 & $5(17.2)$ & $22(75.9)$ & $2(6.9)$ & & \\
\hline \multirow{2}{*}{ Liver volume (mm) } & $\leq 55-110$ & 26 & $4(15.4)$ & $14(53.8)$ & $8(30.8)$ & \multirow[b]{2}{*}{18.913} & \multirow[b]{2}{*}{0} \\
\hline & $>55-110$ & 135 & $28(20.7)$ & $101(74.8)$ & $6(4.4)$ & & \\
\hline \multirow{3}{*}{ Esophagealvarices (severity) } & Minor & 25 & $17(68.0)$ & $8(32.0)$ & $0(0)$ & \multirow{3}{*}{25.476} & \multirow{3}{*}{0} \\
\hline & Medium & 48 & $11(22.9)$ & $33(68.8)$ & $4(8.3)$ & & \\
\hline & Severe & 88 & $6(6.8)$ & $72(81.8)$ & $10(11.4)$ & & \\
\hline \multirow{3}{*}{ Degree of splenomegaly } & 1 & 78 & $20(25.6)$ & $56(71.8)$ & $2(2.6)$ & \multirow{3}{*}{12.947} & \multirow{3}{*}{0.002} \\
\hline & II & 63 & $11(17.5)$ & $46(73.0)$ & $6(9.5)$ & & \\
\hline & III & 20 & $2(10.0)$ & $12(60.0)$ & $6(30.0)$ & & \\
\hline \multirow{3}{*}{ Ascites volume (L) } & $<0.5$ & 127 & $27(21.3)$ & $96(75.6)$ & $4(3.1)$ & \multirow{3}{*}{24.741} & \multirow{3}{*}{0} \\
\hline & $0.5-1$ & 18 & $5(27.8)$ & $9(50.0)$ & $4(22.2)$ & & \\
\hline & $>1$ & 16 & 0 & $10(62.5)$ & $6(37.5)$ & & \\
\hline \multirow{3}{*}{ Child-Pugh classification } & $A$ & 88 & $23(26.1)$ & $63(71.6)$ & $2(2.3)$ & \multirow{3}{*}{20.453} & \multirow{3}{*}{0} \\
\hline & $\mathrm{B}$ & 63 & $9(14.3)$ & $48(76.2)$ & $6(9.5)$ & & \\
\hline & $\mathrm{C}$ & 10 & 0 & $4(40.0)$ & $6(60.0)$ & & \\
\hline \multirow{3}{*}{ Intraoperative bleeding (L) } & $<1$ & 105 & $27(25.7)$ & $70(66.7)$ & $8(7.6)$ & \multirow{3}{*}{7.619} & \multirow{3}{*}{0.022} \\
\hline & 01-Feb & 46 & $5(10.9)$ & $39(84.8)$ & $2(4.3)$ & & \\
\hline & $>2$ & 10 & 0 & $6(60.0)$ & $4(40.0)$ & & \\
\hline \multirow{3}{*}{$\begin{array}{l}\text { Portal venous pressure } \\
\text { (cmH2O) }\end{array}$} & $<24$ & 3 & $3(100)$ & 0 & 0 & \multirow{3}{*}{3.922} & \multirow{3}{*}{0.141} \\
\hline & $24-30$ & 40 & $9(22.5)$ & $29(72.5)$ & $2(5.0)$ & & \\
\hline & $>30$ & 118 & $20(16.9)$ & $86(72.9)$ & $12(10.2)$ & & \\
\hline \multirow{3}{*}{ Operative time (h) } & $<2$ & 17 & $11(64.7)$ & $6(35.3)$ & 0 & & \\
\hline & 02-Apr & 106 & $16(15.1)$ & $82(77.4)$ & $8(7.5)$ & 13.324 & 0.001 \\
\hline & $>4$ & 38 & $5(13.2)$ & $27(71.0)$ & $6(15.8)$ & & \\
\hline & $<1$ & 147 & $32(21.8)$ & $11(76.8)$ & $2(1.4)$ & & \\
\hline $\begin{array}{l}\text { Postoperative wound } \\
\text { bleeding (L) }\end{array}$ & 01-Feb & 8 & 0 & $2(25.0)$ & $6(75.0)$ & 115.282 & 0 \\
\hline & $>2$ & 6 & 0 & 0 & $6(100)$ & & \\
\hline
\end{tabular}

Note: * $55 \mathrm{~mm}$ refers to the longitudinal diameter of the left liver lobe, and $110 \mathrm{~mm}$ diameter refers to the oblique diameter of the right lobes.

Table 1: Relationship between clinical predicators and prognosis

Fib is cryoprecipitate transfusion, and surgery is relatively safe when Fib levels are elevated to $>2 \mathrm{~g} / \mathrm{L}$. Second, thrombocytopenia impairs the important role of platelets in physiological hemostasis. Third, after intraoperative wound bleeding, a large number of coagulation factors in the body are lost and platelets are damaged; despite a massive homologous blood and plasma transfusion, the transfused coagulation factors are wasted due to poor compatibility in the stressful situation, leading to coagulation dysfunction $[5,6]$ and increased bleeding volume. Fourth, surgical procedures may be inappropriate and/or hemostasis is not complete after surgery. Fifth, if a surgical procedure takes too long, a relative increase in intraoperative blood loss can be exhibited. In the single-factor analysis, operative times of $>4 \mathrm{~h}$ exhibited significant correlation with prognosis ( $\mathrm{H}$ value of $11.59, P=0.004$ ). Thus, surgeons and anesthetists should work closely together to perform surgeries under favorable anesthetic conditions to curtail surgery times as much as possible.

Liver atrophy refers to a liver volume that is smaller than normal values due to inflammation, necrosis of liver tissues, liver fibrosis, or nodular regeneration of remnant liver cells caused by various reasons. Severe liver atrophy is the second major risk factor affecting prognosis, and was awarded 3 points in this study. In this study, 26 patients had a longitudinal diameter of the left liver lobe of $\leq 55 \mathrm{~mm}$ and an oblique diameter of the right lobe of $\leq 110 \mathrm{~mm}$; of these patients, $8(30.8 \%)$ died, accounting for $57.1 \%$ of the total deaths. One hundred thirty- 
Citation: Lv YF, Lau WY, Han XY, Gong XG, Liu N, et al. (2014) Prognostic Risk Factors for Surgery in Patients with Cirrhotic Portal Hypertension. J Hypertens 3: 172. doi:10.4172/2167-1095.1000172

Page 4 of 6

\begin{tabular}{|c|c|c|c|c|c|c|c|}
\hline \multicolumn{2}{|l|}{ Parameters } & \multirow{2}{*}{$\begin{array}{c}\text { Total case number } \\
100\end{array}$} & \multirow{2}{*}{$\begin{array}{c}\text { Recovered (\%) } \\
19(19.0)\end{array}$} & \multirow{2}{*}{$\begin{array}{c}\text { Improved (\%) } \\
81(81.0)\end{array}$} & \multirow{2}{*}{$\begin{array}{c}\text { Died (\%) } \\
0\end{array}$} & \multirow{4}{*}{$\begin{array}{c}\text { Value of } \mathbf{H} \\
32.527\end{array}$} & $\mathbf{P}$ \\
\hline \multirow{3}{*}{ WBC (T/L) } & $>4$ & & & & & & \multirow{3}{*}{0} \\
\hline & 03-Apr & 47 & $9(19.1)$ & $34(72.4)$ & $4(8.5)$ & & \\
\hline & $<3$ & 14 & $4(28.6)$ & 0 & $10(71.4)$ & & \\
\hline \multirow{3}{*}{ RBC (G/L) } & $>4$ & 111 & $22(19.8)$ & $89(80.2)$ & 0 & \multirow{3}{*}{37.556} & \multirow{3}{*}{0} \\
\hline & 03-Apr & 36 & $10(27.8)$ & $22(61.1)$ & $4(11.1)$ & & \\
\hline & $<3$ & 14 & 0 & $4(28.6)$ & $10(71.4)$ & & \\
\hline \multirow{3}{*}{ PLT (T/L) } & $>50$ & 102 & $24(23.5)$ & $76(74.5)$ & $2(2.0)$ & \multirow{3}{*}{27.05} & \multirow{3}{*}{0} \\
\hline & $50-30$ & 49 & $6(12.2)$ & 39 (79.6) & $4(8.2)$ & & \\
\hline & $<30$ & 10 & $2(20.0)$ & 0 & $8(80.0)$ & & \\
\hline \multirow{3}{*}{$\mathrm{Hb}(\mathrm{g} / \mathrm{L})$} & $\geq 60$ & 103 & $20(19.4)$ & $80(77.7)$ & $3(2.9)$ & \multirow{3}{*}{23.604} & \multirow{3}{*}{0} \\
\hline & $59-30$ & 43 & $8(18.6)$ & $33(76.7)$ & $2(4.7)$ & & \\
\hline & $<30$ & 15 & $4(26.7)$ & $2(13.3)$ & $9(60.0)$ & & \\
\hline \multirow{3}{*}{ Albumin (g/L) } & $>35$ & 95 & $23(24.2)$ & $66(69.5)$ & $6(6.3)$ & \multirow{3}{*}{7.142} & \multirow{3}{*}{0.028} \\
\hline & $35-30$ & 42 & $9(21.4)$ & $31(73.8)$ & $2(4.8)$ & & \\
\hline & $<30$ & 24 & 0 & $18(75.0)$ & $6(25.0)$ & & \\
\hline \multirow{3}{*}{ Total bilirubin ( $\mu \mathrm{mol} / \mathrm{L})$} & $<34.2$ & 122 & $28(22.9)$ & $87(71.3)$ & $7(5.7)$ & \multirow{3}{*}{7.966} & \multirow{3}{*}{0.099} \\
\hline & $34.2-51.3$ & 31 & $4(12.9)$ & $22(71.0)$ & $5(16.1)$ & & \\
\hline & $>51.3$ & 8 & 0 & $6(75.0)$ & $2(25.0)$ & & \\
\hline \multirow{3}{*}{ Serum creatinine $(\mu \mathrm{mol} / \mathrm{L})$} & $<44$ & 12 & $5(41.7)$ & $5(41.7)$ & $2(16.7)$ & \multirow{3}{*}{5.566} & \\
\hline & $44-115$ & 141 & $27(19.1)$ & $104(73.8)$ & $10(7.1)$ & & 0.062 \\
\hline & $>115$ & 8 & 0 & $6(75.0)$ & $2(25.0)$ & & \\
\hline & $<2.8$ & 15 & $3(20.0)$ & $8(53.3)$ & $4(26.7)$ & & \\
\hline Blood urea (mmol/L) & $2.8-8.2$ & 138 & $29(21.0)$ & $101(73.2)$ & $8(5.8)$ & 2.199 & 0.333 \\
\hline & $>8.2$ & 8 & 0 & $6(75.0)$ & $2(25.0)$ & & \\
\hline & $<20$ & 90 & $22(24.4)$ & $66(73.3)$ & $2(2.2)$ & & \\
\hline PT (s) & $20-30$ & 69 & $11(15.9)$ & $47(68.1)$ & $11(15.9)$ & 13.026 & 0.001 \\
\hline & $>30$ & 2 & 0 & $1(50.0)$ & $1(50.0)$ & & \\
\hline & $>2.0$ & 94 & $23(24.5)$ & $63(67.0)$ & $8(8.5)$ & & \\
\hline FIB (g/L) & $1.5-2.0$ & 41 & $9(21.9)$ & $30(73.2)$ & $2(4.9)$ & 4.98 & 0.083 \\
\hline & $<1.5$ & 26 & 0 & $22(84.6)$ & $4(15.4)$ & & \\
\hline & $<7.35$ & 15 & $2(13.3)$ & $5(33.3)$ & $8(53.3)$ & & \\
\hline Blood pH & $7.35-7.35$ & 121 & $23(19.0)$ & $96(79.3)$ & $2(1.7)$ & 7.212 & 0.027 \\
\hline & $>7.45$ & 25 & $7(28.0)$ & $14(60.0)$ & $4(16.0)$ & & \\
\hline & $<-3$ & 46 & $3(6.5)$ & $33(71.7)$ & $10(21.7)$ & & \\
\hline $\mathrm{BE}(\mathrm{mmol} / \mathrm{L})$ & -6 & 97 & $21(21.6)$ & $74(76.3)$ & $2(2.1)$ & 16.672 & 0 \\
\hline & $>3$ & 18 & $8(44.4)$ & $8(44.4)$ & $2(11.2)$ & & \\
\hline & $>60$ & 159 & $32(20.1)$ & $113(71.1)$ & $14(8.8)$ & & \\
\hline Oxygen partial pressure & $40-60$ & 2 & 0 & $2(100)$ & 0 & 0.85 & 0.669 \\
\hline & $<40$ & 0 & 0 & 0 & 0 & & \\
\hline
\end{tabular}

Table 2: Laboratory parameters and prognosis

\begin{tabular}{|l|c|c|}
\hline Items & $\begin{array}{c}\text { Regression coefficients (b } \\
\text { values) }\end{array}$ & $\boldsymbol{P}$ values \\
\hline Postoperative wound bleeding & 0.356 & 0.000 \\
\hline Degree of liver atrophy & -0.160 & 0.000 \\
\hline Base excess (BE) & -0.123 & 0.000 \\
\hline PLT & 0.065 & 0.015 \\
\hline Intraoperative wound bleeding & 0.062 & 0.014 \\
\hline RBC & 0.053 & 0.024 \\
\hline
\end{tabular}

The 6 risk factors were sorted using the following multiple regression equation: $\hat{Y}=-0.360+0.356 X_{1}-0.160 X_{2}-0.123 X_{3}+0.065 X_{4}+0.062 X_{5}+0.053 X_{0}$

(Note: $X_{1}$ represents postoperative wound bleeding, $X_{2}$ represents the degree of liver atrophy, $X_{3}$ represents $B E, X_{4}$ represents PLT count, $X_{5}$ represents intraoperative wound bleeding, and $X_{6}$ representsRBC count).

$$
\text { Table 3: Results of the logistic regression analysis }
$$

five patients had a longitudinal diameter of the left liver lobe of $>55$ $\mathrm{mm}$ and an oblique diameter of the right lobe of $>110 \mathrm{~mm}$; of these patients, $6(4.4 \%)$ died. There was a significant difference between the two subgroups $(\mathrm{P}<0.001)$. The superior-inferior diameter of the left hepatic lobe is the distance between the superior border and the inferior border of the left lobe, and the oblique diameter of the right lobe is the oblique distance between the most inferior point on the lateral border of the right lobe and the secondary portal of the liver. The normal oblique diameter is $120 \mathrm{~mm}-140 \mathrm{~mm}$. In our research, we found oblique diameters of $\leq 110 \mathrm{~mm}$ and $>110 \mathrm{~mm}$, which were statistically significantly different $(P=0.0001)$. Therefore, $110 \mathrm{~mm}$ was chosen as the criterion. Of course, other indexes to indicate the degree of hepatic cirrhosis exist, such as the size of the hepatic nodules, volume of ascitic fluid, and size of the spleen, but they are difficult to analyze due to the absence of unified objective standards. Multi-slice spiral CT scans may serve as a better method for measuring liver size, $[7,8]$ but CT scans have only recently begun to be performed on many of our patients, and most of the existing scans were not multi-slice spiral CT scans. In contrast, each enrolled patient had a B ultrasound examination. Therefore, we chose to use the results of the B ultrasound and CT examination for comparison, as such results had statistically significant differences. Due to poor liver reserve functions and compensatory functions after severe liver atrophy, postoperative prognosis is generally 


\begin{tabular}{|l|c|c|}
\hline Items & Severity & Scores \\
\hline Postoperative major wound bleeding & $>2 \mathrm{~L}$ & 3 \\
\hline Severe liver atrophy & $\leq 55$ and $110 \mathrm{~mm}^{*}$ & 3 \\
\hline BE & $<-3$ & 2 \\
\hline PLT & $<30,000$ & 2 \\
\hline Intraoperative major wound bleeding & $>2 \mathrm{~L}$ & 2 \\
\hline RBC & $<3(\mathrm{G} / \mathrm{L})$ & 1 \\
\hline Total & & 14 \\
\hline
\end{tabular}

Note: * $55 \mathrm{~mm}$ refers to the longitudinal diameter of the left liver lobe, and $110 \mathrm{~mm}$ diameter refers to the oblique diameter of the right lobes. Table 4: Scores of the6 risk factors

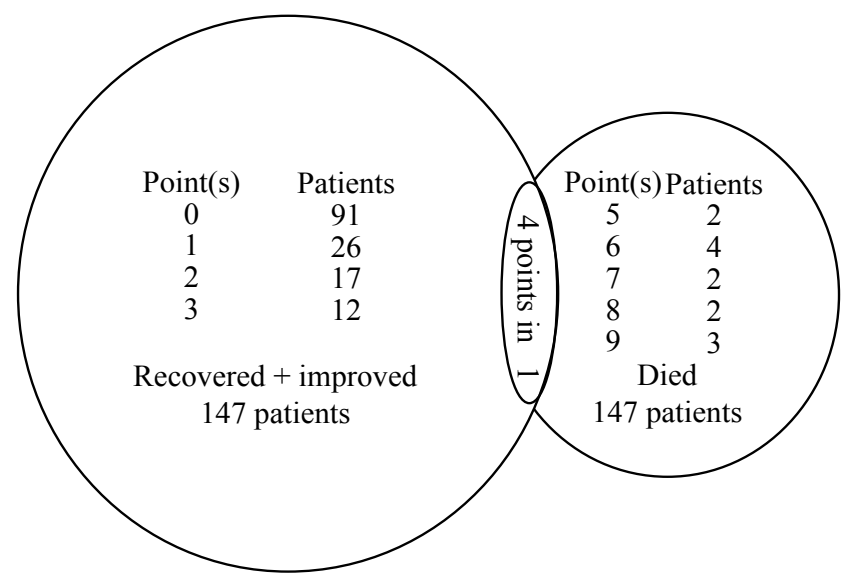

Figure 1: Group scores

undesirable [9]. Generally, if a logistic regression coefficient of -0.160 indicates more severe liver atrophy, thus patients are more prone to uncontrollable major bleeding and liver failure, which increases mortality [10]. The authors once personally encountered a single case of macronodular-type, hard texture, severe liver atrophy with pancytopenia, and a PLT of $15 \times 10^{9} / \mathrm{L}$. Immediately upon removing the patient from the operating room following splenectomy and portoazygous devascularization, $600 \mathrm{ml}$ of blood abruptly disgorged from the abdominal drainage tube; an abdominal exploration was immediately performed, which revealed "sweat-like" extensive oozing of blood from the serosa. There was no obvious bleeding from the surgical wound, and because it was unable to be treated, the patient died the next day. From the authors' understanding, a "sweat-like" extensive oozing of blood during surgery is a sign of poor prognosis. For patients with macronodular type (diameter $>10 \mathrm{~mm}$ ) severe liver atrophy, remarkably abnormal coagulation factors and PLT $<20 \times 10^{9} / \mathrm{L}$, surgery should be contraindicated.

BE levels significantly lower than normal limits and falling into the acidemia category, was the third major risk factors, and was awarded 3 points. Acidosis is a very serious complication that disturbs the metabolism of the body [11]. Funk et al. regarded that acidemia or lactic acidosis may increase mortality owing to liver cirrhosis and blood loss during episodes of hepatic decompensation [12]. The logistic regression coefficient of $\mathrm{BE}$ was - 0.123. A lower $\mathrm{BE}$ means more excessive acid, which results in acid-base imbalance, and is detrimental to the body, [13] and it is a significant factor associated with death [14].

A low PLT count was the fifth risk factor for prognosis, and was awarded 2 points. A PLT count of $<30 \times 10^{9} / \mathrm{L}$ was clearly linked to prognosis $(P<0.05)$ both in the single-factor analysis $(\mathrm{H}$ value of 7.67 , $P=0.022)$ and the multi-factor logistic regression analysis. Karasu et al. regarded that PLT count reduction was a common complication of liver cirrhosis and splenomegaly [15]. It is not only associated with the splenic retention theory, blood cell aggregation, enhanced phagocytosis, and destruction of macrophages, [16] but also with bone marrow compensation and adjustment [17]. Thus, a low PLT count was the fifth risk factor associated with prognosis [18]. Preoperative PLT transfusion is required to elevate the PLT count to above $50 \times 10^{9} / \mathrm{L}$. An increased postoperative PLT count has also been demonstrated to be a risk factor $[19,20]$.

Low $\mathrm{RBC}$ count was the seventh risk factor impacting prognosis, which was awarded 1 point. An RBC count of $<3(\mathrm{G} / \mathrm{L})$ was associated with prognosis in both the single-factor analysis ( $\mathrm{H}$ value of 47.556 , $P=0.000)$ and multi-factor logistic regression analysis $(P=0.015)$. The main functions of the $\mathrm{RBC}$ are to transport $\mathrm{O}_{2}$ and participate in $\mathrm{CO}_{2}$ excretion [21]. Transportation of $\mathrm{O}_{2}$ by RBCs is achieved by intracellular $\mathrm{Hb}$. If the $\mathrm{RBCs}$ are reduced in number or ruptured, $\mathrm{Hb}$ will escape, and gas transportation functionality can be lost; this may cause ischemia and hypoxia of body tissues and result in multiple organ failure. Therefore, preoperative $\mathrm{RBC}$ transportation is required to elevate the RBC count to $>3 \mathrm{G} / \mathrm{L}$.

In the single-factor analysis, prolonged PT was clearly associated with prognosis, but it was eliminated in the multi-factor logistic regression analysis. This may have been related to strictly adhering to the principle of no surgery for cases with a prolonged PT of more than 30 seconds preoperatively. In this study, there were only 2 cases of prolonged PT greater than 30 seconds, which is too small for statistical analysis. In actuality, the normality of PT and Fib is more important than the decrease in the number of blood cells. Recently, a patient, aged 22 years, with a WBC of $1.35 \times 10^{9} / \mathrm{L}$, an $\mathrm{RBC}$ of $2.42 \times 10^{12} / \mathrm{L}$, a PLT of $27 \times 10^{9} / \mathrm{L}$, and an $\mathrm{Hb}$ of $50 \mathrm{~g} / \mathrm{L}$, but normal PT, Fib, and liver function pre-operatively, recovered successfully after splenectomy with gastroesophageal devascularization.

Theoretically, an increase in portal vein pressure could increase the incidence of hemorrhage and death, but in this study, there were no statistically significant differences in the univariate or multivariate analyses $(P>0.05)$. This might be due to the small number of patients who underwent surgeries for massive gastrointestinal hemorrhage.

Even though patient nutrition, financial status, constitutional diathesis, psychological factors, and medical conditions may also be related to prognosis, [22] the above mentioned 7 quantifiable risk factors cannot be ignored. They are critical factors affecting the surgical prognosis of cirrhotic portal hypertension. In order to verify the accuracy and operability of this model, data from 15 patients with portal hypertension admitted after January 2011 were analyzed directly using the 7 risk factors for surgical outcome derived statistically. Of the 15 patients, only one patient, with a total score of 7 points, did not improve. The other 14 patients had total scores of less than 4 points and were discharged. Of the 14 patients, 9 were cured and 5 had improved. This verifies the contention proposed in this study that the total score must be controlled to be $<4$ to improve the cure rate.

\section{References}

1. Yunfu Lv (2014) Causes of peripheral blood cytopenias in patients with live cirrhosis portal hypertension and cilinical significances. Open J Endocrine Metabolic Dis 4:85-89

2. Yunfu L, Xinqiu L, Weiwei H, Baochun W, Yijun Y (2007) Changes of peripheral blood cells in patients with hypersplenism secondary to portal hypertension. Chin J Gen Surg 22: 702-703.

3. Zhang M, Shen W (2007) Etiology analysis of liver cirrhosis of 824 cases Chinese Selected Master's Theses Full-Text Databases 10-14. 
Citation: Lv YF, Lau WY, Han XY, Gong XG, Liu N, et al. (2014) Prognostic Risk Factors for Surgery in Patients with Cirrhotic Portal Hypertension. J Hypertens 3: 172. doi:10.4172/2167-1095.1000172

4. Borie F, Bouvier AM, Herrero A, Faivre J, Launoy G, et al. (2008) Treatment and prognosis of hepatocellular carcinoma: a population based study in France. J Surg Oncol 98: 505-509.

5. Schleinzer W (1991) Concept of autologous transfusion. Biomed Prog4:1-8.

6. Martin J, Robitaille D, Perrault LP, Pellerin M, Pagé P, et al. (2000) Reinfusion of mediastinal blood after heart surgery. J ThoracCardiovascSurg 120: 499504.

7. Abdalla EK, Denys A, Chevalier P, Nemr RA, Vauthey JN (2004) Total and segmental liver volume variations: implications for liver surgery. Surgery 135 $404-410$

8. Jin Ping Li, HuiJie Jiang (2010) Clinical application of measurement of liver volume by multi-slice spiral CT. World Chin J Digestol18:1786-1791.

9. Takayasu K, Arii S, Ikai I, Omata M, Okita K, et al. (2006) Prospective cohort study of transarterial chemoembolization for unresectable hepatocellular carcinoma in 8510 patients. Gastroenterology 131: 461-469.

10. Komori H, Hirasa M, Takakuwa H, Ibuki Y, Kudo M, et al. (1986) Concept of the clinical stages of acute hepatic failure. Am J Gastroenterol 81: 544-549.

11. Vengerov I, Nagibina MV, Chentsov VB, Migmanov TE, Menushenkova SA et.al. (2008) Clinical implications of lactic acidosis in purulent meningitis. Klin Med (Mosk) 86:43-46.

12. Funk GC, Doberer D, Kneidinger N, Lindner G, Holzinger U, et al. (2007) Acid-base disturbances in critically ill patients with cirrhosis. Liver Int 27: 901 909

13. Libório AB, Daher EF, de Castro MC (2008) Characterization of acid-base status in maintenance hemodialysis: physicochemical approach. J Artif Organs 11: 156-159.
14. Lee SW, Hong YS, Park DW, Choi SH, Moon SW, et al. (2008) Lactic acidosis not hyperlactatemia as a predictor of in hospital mortality in septic emergency patients. Emerg Med J 25: 659-665.

15. Karasu Z, Gurakar A, Kerwin B, Hulagu S, Jazzar A, et al. (2000) Effect of transjugular intrahepatic portosystemic shunt on thrombocytopenia associated with cirrhosis. Dig Dis Sci 45: 1971-1976.

16. Yan F, Li W, Chen JT, Zeng YM, Guo YW, et al. (2006) [CDNA microarraybased screening of differentially expressed genes in macrophages in the spleen of patients with portal hypertension and hypersplenism]. Nan Fang $\mathrm{Yi}$ Ke Da Xue Xue Bao 26: 1548-1551.

17. Yun-fu L, Xin-qiu L, Xian-he X, Xiao-guang G, Xiao-lan T, et.al. (2009) Porta Hypertension Splenomegaly is not Always Associated with Hematocytopenia. J US-Chin Med Sci 6: 28-30.

18. DjordjeviÄ J, Svorcan P, VriniÄ D, DapceviÄ B (2010) [Splenomegaly and thrombocytopenia in patients with liver cirrhosis]. Vojnosanit Pregl 67: 166 169 .

19. Matsuura T, Hayashida M, Saeki I, Taguchi T (2010) The risk factors of persistent thrombocytopenia and splenomegaly after liver transplantation. PediatrSurglnt 26: 1007-1010.

20. Lu YF, Li XQ, Han XY, Gong XG, Chang SW (2013) Peripheral blood cell variations in cirrhotic portal hypertension patients with hypersplenism. Asian Pac J Trop Med 6: 663-666.

21. Yao T, (2003) Physiology (5thedn) People's Health Publishing, Beijing China 52-56.

22. Yang Z, Qiu F (2003) Studies on the outcome of portal hypertension. Journa of Abd Surg 16: 68-70. 